\title{
Protein kinase Ds promote tumor angiogenesis through mast cell recruitment and expression of angiogenic factors in prostate cancer microenvironment
}

\author{
Wanfu Xu ${ }^{1,4 \dagger}$, Jiabi Qian ${ }^{1,4 \dagger}{ }^{\text {, Fangyin Zeng }}{ }^{2 \dagger}$, Songyu Li ${ }^{1}$, Wenjing Guo ${ }^{1}$, Liping Chen ${ }^{1}$, Guihuan Li ${ }^{1}$,
} Zhishuai Zhang ${ }^{1}$, Qiming Jane Wang ${ }^{3}$ and Fan Deng ${ }^{1 *}$

\begin{abstract}
Background: Mast cells are being increasingly recognized as critical components in the tumor microenvironment. Protein Kinase D (PKD) is essential for the progression of prostate cancer, but its role in prostate cancer microenvironment remains poorly understood.

Methods: The expression of PKD, mast cells and microvessel density were examined by IHC. The clinical significance was determined by statistical analyses. The biological function of PKD and the underlying mechanisms were investigated using in vitro and in vivo models.

Results: PKD2/3 contributed to MCs recruitment and tumor angiogenesis in the prostate cancer microenvironment. Clinical data showed that increased activation of PKD at Ser744/748 in prostate cancer was correlated with mast cell infiltration and microvascular density. PKD2/3 silencing of prostate cancer cells markedly decreased MCs migration and tube formation of HUVEC cells. Moreover, PKD2/3 depletion not only reduced SCF, CCL5 and CCL11 expression in prostate cancer cells but also inhibited angiogenic factors in MCs. Conversely, exogenous SCF, CCL5 and CCL11 reversed the effect on MCs migration inhibited by PKD2/3 silencing. Mechanistically, PKD2/3 interacted with Erk1/2 and activated Erk1/2 or NF-KB signaling pathway, leading to AP-1 or NF-KB binding to the promoter of scf, ccl5 and ccl11. Finally, PKD-specific inhibitor significantly reduced tumor volume and tumor growth in mice bearing RM-1 prostate cancer cells, which was attributed to attenuation of mast cell recruitment and tumor angiogenesis.
\end{abstract}

Conclusions: These results demonstrate a novel PKDs function that contributes to tumor angiogenesis and progression through mast cells recruitment in prostate cancer microenvironment.

Keywords: Protein kinase D(PKD), Mast cells(MCs), Angiogenesis, Prostate cancer

\section{Background}

Prostate cancer $(\mathrm{PCa})$ is the most common diagnosed cancer and accounts for the second most frequent cause of death from cancer in men in western countries [1,2]. In China, prostate cancer morbidity and mortality are also increasing in the last decade [3]. A growing body of evidence indicated that chronic inflammation mediated

\footnotetext{
* Correspondence: fandeng@smu.edu.cn

tWanfu Xu, Jiabi Qian and Fangyin Zeng contributed equally to this work.

'Department of Cell Biology, School of Basic Medical Sciences, Southern

Medical University, Guangzhou 510515, China

Full list of author information is available at the end of the article
}

by several immune cells, such as macrophages, $\mathrm{T}$ cells, neutrophils, and mast cells (MCs) has been shown to play an important role in prostate cancer development and progression $[4,5]$. However, the contribution of specific immune cells to the pathogenesis and progression of prostate cancer remained obscure.

Mast cells, which function as immune regulatory cells in allergic reactions and autoimmunity [6, 7], are increasingly recognized as critical components of the tumor stromal microenvironment in a number of human cancers $[8,9]$. In many cancers, increased mast cell accumulation has been correlated with poor prognosis [10, 11], angiogenesis,

(c) The Author(s). 2019 Open Access This article is distributed under the terms of the Creative Commons Attribution 4.0 International License (http://creativecommons.org/licenses/by/4.0/), which permits unrestricted use, distribution, and 
tissue remodeling and immunomodulation. Current data also showed that MCs may exert pro- or anti-tumoral roles, depending on tumor type, microenvironment signals and neighboring interacting cells $[9,12]$. In prostate cancer, several studies have tried to address the actual role of MCs in promoting or suppressing cancer, but they did not assess the correlation of mast accumulation with prognosis $[13,14]$. Recently, peritumoral MCs were shown to enhance angiogenesis and tumor growth in the orthotopic AT-1 rat prostate tumor model, and MCs were seen recruited in the peritumoral compartment in men during the formation of androgen independent prostate cancer. In contrast, high MCs numbers in the intratumoral compartment were shown to be associated with a favorable outcome in patients $[15,16]$. These studies suggest that the actual role of MCs in prostate cancer is indeed context, and regulation of mast cells recruitment and consequent function are needed to be fully deciphered in the prostate cancer microenvironment.

The protein kinase D (PKD) family of serine/threonine kinases, which can be activated by gastrointestinal hormones, comprises three distinct isoforms that modulate a variety of cellular processes. Aberrant PKD activity and expression have been demonstrated in tumor cell lines and pancreatic tumor tissues [17], as well as those from the skin [18], breast [19], and prostate [20]. In particular, PKD has been implicated in many aspects of tumorigenesis and progression, including survival, growth and invasion [20]. Our and other's lab have shown that PKD plays an important role in the pathogenesis of prostate cancer and targeted PKD inhibition potently blocks cell proliferation and survival in prostate cancer $[20,21]$. Recent evidence has shown that PKD isoenzymes regulate vascular endothelial growth factor-A (VEGF-A)-induced endothelial cell proliferation, migration, and angiogenesis [22]. However, whether PKDs regulate tumor angiogenesis through stromal cells in the prostate cancer microenvironment remains unknown.

In this study, we evaluated the role of PKDs in the recruitment of MCs and MCs-mediated angiogenesis in prostate cancer microenvironment. Our study reveals a novel mechanism of PKDs in promoting tumor angiogenesis by enhancing recruitment of MCs and expression of angiogenic factors in the prostate cancer microenvironment.

\section{Methods}

\section{Cell lines and cultures}

The prostate cancer cell lines, PC-3, DU145 and RM1, and the mouse mast cell lines P815 were obtained from the American Type Culture Collection and cultured in Dulbecco's modified Eagle's medium (DMEM, Gibco) supplemented with $10 \%$ fetal bovine serum (FBS, Gibco) in a humidified incubator at $37^{\circ} \mathrm{C}$ with $5 \% \mathrm{CO}_{2}$. All the cell lines identity was verified before experiments.

\section{Plasmid and siRNA transfection}

The plasmid GFP-C2, GFP-PKD1, GFP-PKD2 and GFP-PKD3, kindly gifted by Prof. Q. Jane Wang, were transfected into cells transiently by Hilymax (Dojindo, kumamoto, Japan) as suggested by the user manual. siRNA, from GenePharma, was transfected into cells using Lipofectamine 3000 reagent (Invitrogen), according to the manufacturer's instructions. The siRNA sequence is listed in Additional file 1: Table S1.

\section{Isolation and culture of bone marrow derived mast cells} C57BL/6 mice were killed and their femurs were obtained in aseptic conditions. Marrow was expelled with culture medium, and bone marrow cells were then washed, spun and cultured in RPMI 1640 supplemented with $10 \%$ FBS. The cells were cultured in the presence of IL-3 and SCF (10 ng/mL each, PeproTech, Rocky Hill, $\mathrm{NJ}$ ) (these cells are referred to here as BMMCs) as described previously [23] .

\section{Chemotaxis assay}

The chemotaxis of P815 MCs was monitored using 24-well with a pore size of $8 \mu \mathrm{m}$ in chambers. Briefly, the supernatant was added to chambers below of the filter, while P815 MCs was added to upper chambers. After $8 \mathrm{~h}$ at $37^{\circ} \mathrm{C}$ and in $5 \% \mathrm{CO}_{2}$, the filters were fixed and stained in a dye solution containing 20\% $(v / v)$ methanol and $0.1 \%(w / v)$ crystal violet. The cells that had migrated were imaged and counted.

\section{RNA extraction and quantitative real-time PCR}

Total RNA was extracted from cultured cells with TRIZOL reagent (Invitrogen), according to the manufacturer's protocol. All cDNA samples were prepared using an All-in-one First-stand cDNA synthesis kit (GeneCopoeia, MD, USA). Quantitative real-time PCR (RT-qPCR) analyses were performed with an All-in-one qPCR mix (GeneCopoeia), according to manufacturer's instructions using an ABI StepOnePlus $^{\mathrm{Tm}}$ qPCR system. Primers and gene ID are listed in Additional file 1: Table S2.

\section{Endothelial cell tube formation assay}

96-well plates were coated with Matrigel Basement Membrane Matrix (BD Biosciences) and then allowed to polymerize at $37^{\circ} \mathrm{C}$ for at least $30 \mathrm{~min}$. HUVECs were treated with conditional medium for $8 \mathrm{~h}$, tubes formation of HUVECs can be visualized and the number of nodes (defined as when at least three cells formed a single point) per image was quantified as described [24]. 


\section{Enzyme-linked immunosorbent assays (ELISA)}

Quantitative measurement of cytokines, including stem cell factor (SCF), Chemokine ligand 5 (CCL5), C-C motif chemokine 11(CCL11) and vascular endothelial growth factor (VEGF) secreted into conditioned medium was determined using ELISAs, according to the manufacturer's protocol (BOSTER).

\section{Immunoprecipitation and immunoblotting assays}

Cell lysates were extracted in IP-lysis buffer $(50 \mathrm{mM}$ Tris-HCl, pH: $7.5 ; 150 \mathrm{mM} \mathrm{NaCl} ; 1 \mathrm{mM}$ ethylenediaminetetraacetic acid-2Na (EDTA-2Na); $10 \%$ Triton $\mathrm{X}-100 ; 0.5 \mathrm{mM} \quad \mathrm{Na}_{4} \mathrm{P}_{2} \mathrm{O}_{7} \cdot 10 \mathrm{H}_{2} \mathrm{O} ; 1 \mathrm{mM} \mathrm{C}_{3} \mathrm{H}_{7} \mathrm{Na}_{2} \mathrm{O}_{6}$ $\left.\mathrm{P}_{5}\left(\mathrm{H}_{2} \mathrm{O}\right) ; 1 \mathrm{mM} \mathrm{Na} \mathrm{VO}_{4}\right)$, supernatants were clarified by centrifugation at $12000 \mathrm{~g}$ and incubated at $4{ }^{\circ} \mathrm{C}$ with the corresponding antibodies overnight, PKD2(CST, 8188,1:2000 for WB), PKD3(CST, 5655,1:2000 for WB), $\alpha$-tubulin(Ray, RM2007,1:5000 for WB), VEGF(Abclonal, A12303,1:2000 for WB), Erk1/2(Abclonal, A10613,1:2000 for WB), p-Erk1/ 2(CST, 4370, 1:2000 for WB), p-c-Jun(Ser63)(Bioworld, BS4045; Abclonal, AP0048, 1:2000 for WB), p-c-Jun(Ser73)(Bioworld, BS4046; Abclonal, AP0119, 1:2000 for WB), p-c-Fos(Ser32)(CST, 5348; Immunoway, YP0442, 1:1000 for WB), p65(CST, 8242, 1:2000 for WB), p-p65(Ser536)(CST, 3033, 1:2000 for WB), p-p65(Ser276)(CST, 3037, 1:2000 for WB), p38(CST, 8690, 1:2000 for WB), c-Jun(CST, 9165, 1:2000 for WB), c-Fos(CST, 2250, 1:2000 for WB), after a further $2 \mathrm{~h}$ incubation with $20 \mu \mathrm{l}$ of protein A/G (GE Healthcare). The mix was lysed with $2 x$ laemmli sample buffer and analyzed by immunoblotting to detect proteins. Briefly, the protein was transferred to a $0.22 \mu \mathrm{m}$ nitrocellulose transfer membrane. The membrane was blocked with $5 \%(w / v)$ milk in PBS/ $0.05 \%(v / v)$ Tween-20 and then incubated with the indicated antibody overnight. This was followed by incubation with a horseradish peroxidase secondary antibody (Jackson ImmunoResearch) for $1 \mathrm{~h}$ at room temperature. Proteins were detected using enhanced chemiluminescence substrates (Perkin Elmer).

\section{Chromatin immunoprecipitation (ChIP) assays}

ChIP assays were performed in DU145 cells by using an EZ-Zyme Chromatin Prep Kit (Millipore) as pervious work [25]. Briefly, $1.0 \times 10^{7}$ cells were cross-linked with $1 \%(\mathrm{w} / \mathrm{v})$ formaldehyde for $10 \mathrm{~min}$ and then quenched in $0.125 \mathrm{M}$ glycine for $5 \mathrm{~min}$. Cells were lysed and digested to collect the chromatin. IP was carried out by using the indicated antibody overnight. The precipitated DNAs were analyzed and quantified by using real-time PCR analysis. Primer sequences are listed in Additional file 1: Table S3.
Immunohistochemistry (IHC) of human tissue microarrays A human prostate cancer tissue microarray was purchased from Alenabio (Additional file 1: Table S4 and Additional file 2: Supplementary data of clinical array). Prostate cancer samples were immunostained against indicated antibodies. Briefly, the slides were dewaxed and rehydrated in distilled water, sections were immersed in citrate buffer $\left(\mathrm{C}_{6} \mathrm{H}_{5} \mathrm{Na}_{3} \mathrm{O}_{7} \cdot 2 \mathrm{H}_{2} \mathrm{O}\right)$ and then microwaved for $20 \mathrm{~min}$ for antigen retrieval. Endogenous peroxidase activity was blocked with $0.5 \%(v / v) \quad \mathrm{H}_{2} \mathrm{O}_{2}$. The slides were then transferred into a humidified chamber, incubated with $5 \%(\mathrm{v} / \mathrm{v})$ horse serum for $30 \mathrm{~min}$ and then incubated with primary antibodies overnight at $4{ }^{\circ} \mathrm{C}$. After primary antibody CD31(Sangon Biothch, D260721,1:200 for IHC), c-Kit(Sangon Biothch, D155222,1:200 for IHC, phosphor-PKD Ser744/748(CST, 2051, 1:200 for IHC) incubation, the slides were immersed in peroxidase-labeled secondary antibody for $30 \mathrm{~min}$ at room temperature. To detect the antibody-conjugated antigen reaction, the sections were incubated in 3-amino-9-ethylcarbazole substrate-chromogen for 30 min and counterstained with hematoxylin.

\section{In vivo mice experiments}

All animal experiments were conducted according to Southern Medical University's animal institutional regulations and the relevant authorities approved the research protocols. Briefly, $1 \times 10^{4}$ RM1 prostate cancer cells were injected into both flanks of C57BL/6 mice. Once tumors were palpable, mice were randomized into the following groups (5 mice per group): (A) control (vehicle; 5\% dextrose); (B) $0.36 \mathrm{mg} / \mathrm{kg}$ CRT0066101 and (C) $0.72 \mathrm{mg} / \mathrm{kg}$ CRT0066101 (dissolved in 5\% dextrose) administered by intraperitoneal injection once daily. Tumor volumes were monitored for the next 2 weeks. After tumors were excised, tumor weight was measured and tumor volume was calculated according to the formula $\left(\mathrm{W}^{2} \times \mathrm{L}\right) / 2$, where $\mathrm{W}$ is width and $\mathrm{L}$ is length of the tumor [26].

\section{Statistical analysis}

All statistical analyses were completed using IBM SPSS Statistics 21. All statistical graphing was completed using GraphPad Prism 6 software. The t test was used to determine the significance of differences in the qPCR assay. One-way ANOVA was performed on data from chemotaxis, ELISA assays and endothelial cell tube formation assay. For correlation analysis, the Pearson and Spearmen test was used. $p$ value of less than 0.05 was considered statistically significant. 


\section{Results}

PKD activation is correlated with microvascular density and MCs recruitment in prostate cancer

Accumulating evidence demonstrated that tumor-infiltrating activated MCs were significantly associated with progression of solid tumors through various mechanisms including promoting tissue remodeling, immune suppression and angiogenesis [27-29]. We have previously found that PKD1 and PKD3 are upregulated in prostate cancers [20], but another data also showed that PKD1 was downregulated in metastatic prostate cancer [30]. Meanwhile, according to TCGA data [Prostate Adenocarcinoma (TCGA, PanCancer Atlas)], PKD1/ $2 / 3$ expression in prostate cancer, at mRNA levels, are upregulated in about 4-5\% tumors (Additional file 3: Figure S1), suggesting that it is not so much about overexpression or amplification in tumors, the aberrant activation of PKD1/2/3 may plays a more important role in tumor progression. To explore the relationship of PKD activation with MCs recruitment and tumor angiogenesis, we detected the phosphorylation of PKD, microvessel density (MVD), and MCs by IHC in two sets of 24 tissue microarrays of human prostate cancers (Additional file 1: Table S5). As shown in Fig. 1a-c, the phosphorylation of activation loop at s744/748 for PKD (p-PKDser744/748), CD31 (an endothelial cell marker) and c-Kit (a MCs marker) were significantly increased in prostate cancers compared with normal prostate tissue. We then detected autophosphorylation of PKD at s916 by IHC, as shown in Additional file 4: Figure S2, there is no difference for autophosphorylation of PKD at s916 between normal prostate tissue and prostate cancers. Interestingly, the phosphorylation of activation loop at s744/748 for PKD was positively correlated with MVD in prostate cancers compared with normal prostate tissues (Fig. 1d, Additional file 1: Table S5). These data suggested that PKD promoted tumor angiogenesis through regulating $\mathrm{MCs}$ and $\mathrm{MVD}$ in the tumor microenvironment.

\section{Inhibition of PKD expression and activity in prostate cancer cells decrease chemotactic migration of MCs}

To explore possible role of PKDs in the MCs recruitment in the prostate microenvironment, we investigated the effect of PKDs in prostate cancer cells on MCs migration using co-cultured system. As shown in Fig. 2a, the conditional medium (CM) from PKD2- or PKD3-depleted PC-3 M or DU145 cells significantly reduced the chemotactic migration of P815 MCs compared with CM from the si-CTL control cells. Similarly, chemotactic migration of P815 MCs (Additional file 5: Figure S3A) or BMMCs (Additional file 5: Figure S3B) isolated from mice were also significantly inhibited by CM from DU145 cells or PC-3 M cells treated with a
PKD specific inhibitor kb-NB142-70 [31]. These results suggest that PKD of tumor cells may contribute to the MCs recruitment through specific chemokines secretion in prostate cancer cells.

PKD2 and PKD3 of prostate cancer cells promote HUVEC cells tube formation via induction of angiogenic factors in MCs

MCs appear at the edges of invasive tumors (peritumoral mast cells) [32, 33] in various tumor models and facilitate angiogenesis at least in part by triggering the release of angiogenic factor VEGF [34]. We have previously demonstrated that PKD2 or PKD3 did not promote angiogenic factor VEGF expression in prostate cancer cells [35], which is confirmed by the ELISA results that depletion of PKD2 or PKD3 has no effect on VEGF secretion in either prostate cancer cells (Additional file 6: Figure S4A-B) or mast cells (Additional file 6: Figure S4C-D). Similarly, the CM from DU145 cells transfected with GFP-PKD2 or GFP-PKD3 failed to alter tube formation in HUVEC cells (Additional file 4: Figure S4E-F). In order to investigate whether PKD2 and PKD3 of prostate cancer cells regulate HUVEC cells tube formation in MCs-dependent manner, we first detected the effect of PKD2 and PKD3 of prostate cancer cells on the angiogenic factors expression in the P815 MCs. PKD2 and PKD3 silencing were verified by Western blotting (Fig. 2b). Compared with control group, mRNA level of VEGF (Fig. 2c), and other angiogenic factors such as TNF- $\alpha$, IL-6, IL-8 and FGF-2 (Additional file 7: Figure S5) was significantly reduced in the P815 MCs treated with CMs from DU145 cells transfected with siRNA of PKD2 and/or PKD3.

We then explored whether PKD2/3 of prostate cancer cells mediated HUVECs tube formation through upregulation of VEGF expression in mast cells. After transfection with siRNA of PKD2, PKD3 in PC-3 M cells (Fig. 2d, up), and with siRNA of VEGF in P815 MCs (Fig. 2d, bottom), we collected the corresponding supernatant and co-cultured with HUVECs. As expected, the tube formation of HUVECs was not affected by the CM from PC-3 M cells transfected with siRNA of PKD2 and/or PKD3 using co-cultured with MCs (Fig. 2e, left column). However, the tube formation of HUVECs was completely diminished in co-cultured medium of PC-3 M cells transfected with siRNA of PKD2 or PKD3 and mast cells with VEGF silencing (Fig. 2c, middle column of Fig. 2e), which were reversed by the addition of rVEGF into co-culture medium of HUVECs and MCs (Fig. 2E, right column), the corresponding statistics was shown in Fig. 2f. These data indicated that PKDs of prostate cancer cells contributed to the tumor angiogenesis through regulating angiogenic 


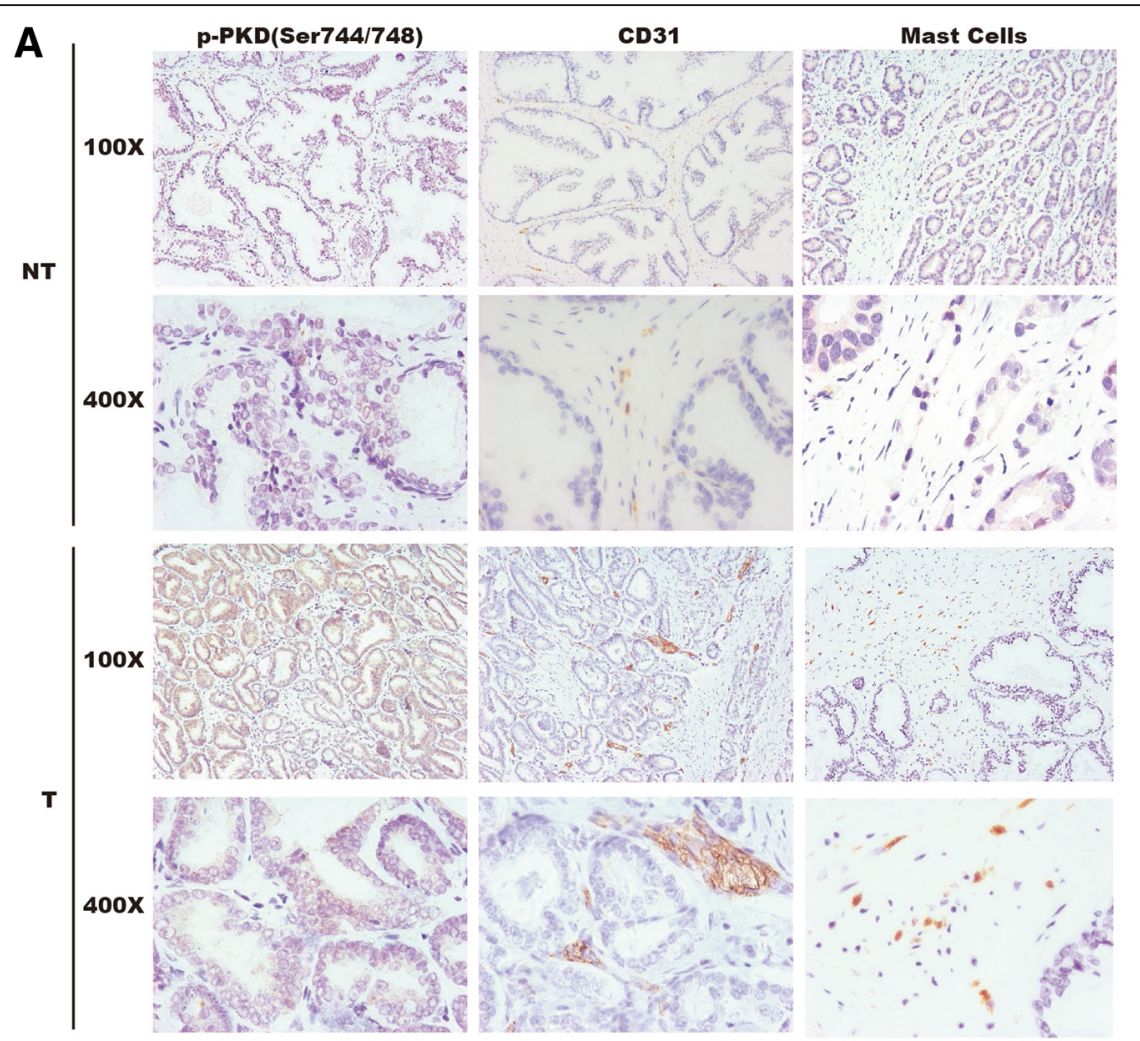

B

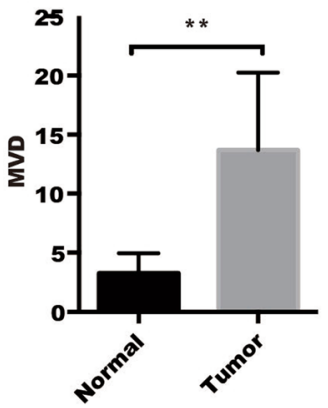

C

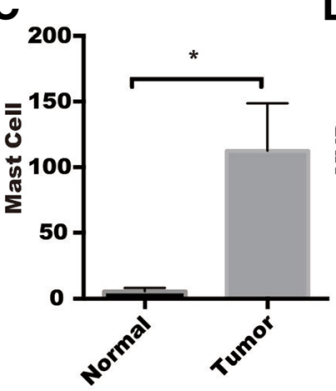

D

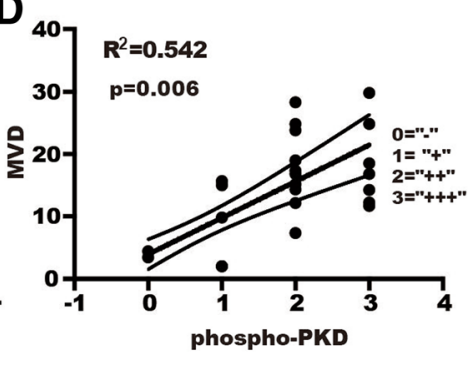

Fig. 1 Activation of PKD at Ser744/748 is correlated positively with mast cells infiltration and microvessel density in prostate cancer. a Representative images of immunohistochemistry staining for activation of PKD (phospho-PKD Ser744/748), abundance of angiogenesis (CD31 marker) and of mast cells (c-Kit) in prostate cancer tissue and paired control. Quantification of MVD (b) and mast cells (c) in clinical tissue microarrays between cancer tissues ( $n=20$ ) and paired controls $(n=4)$ were analyzed by t-tests. ${ }^{* *} p<0.01,{ }^{*} p<0.05$. $\mathbf{d}$ A positive correlation was presented between phospho-PKD and MVD

factors secretion of mast cells in prostate cancer microenvironment.

\section{PKD2 and PKD3 enhance chemotactic migration of mast} cells via SCF, CCL5 and CCL11 secretion in prostate cancer cells

Given that multiple autocrine or paracrine chemokines such as SCF, CCL5 and CCL11 mediated MCs migration and recruitment [23, 36, 37], so we verified whether PKD2 or PKD3 could regulate these chemokines expression in the prostate cancer cells. RT-qPCR showed that mRNA level of $s c f$, $c c l 5$, and ccl11 was significantly suppressed in DU145 (Fig. 3a, left panel) or PC-3 M cells (Fig. 3b, left panel) with knockdown of PKD2 or PKD3. Similarly, ELISA assay also found that PKD2 or PKD3 depletion markedly decreased the secretion of SCF, CCL5 and CCL11 in DU145 (Fig. 3a, right panel) or PC-3 M cells (Fig. 3b, right panel). Western blotting was performed to confirm knockdown efficiency (Fig. 3c).

To further clarify whether PKD2/3 mediated chemotactic migration of MCs through upregulation of SCF, CCL5, and CCL11 in prostate cancer, we performed migration assay for P815 MCs in a transwell plate. As expected, chemotactic migration of P815 MCs was inhibited by the CM from DU145 cells with PKD2 and/ or PKD3 silencing, while these effects were rescued by the addition of SCF, CCL5 and CCL11 in the CM, 


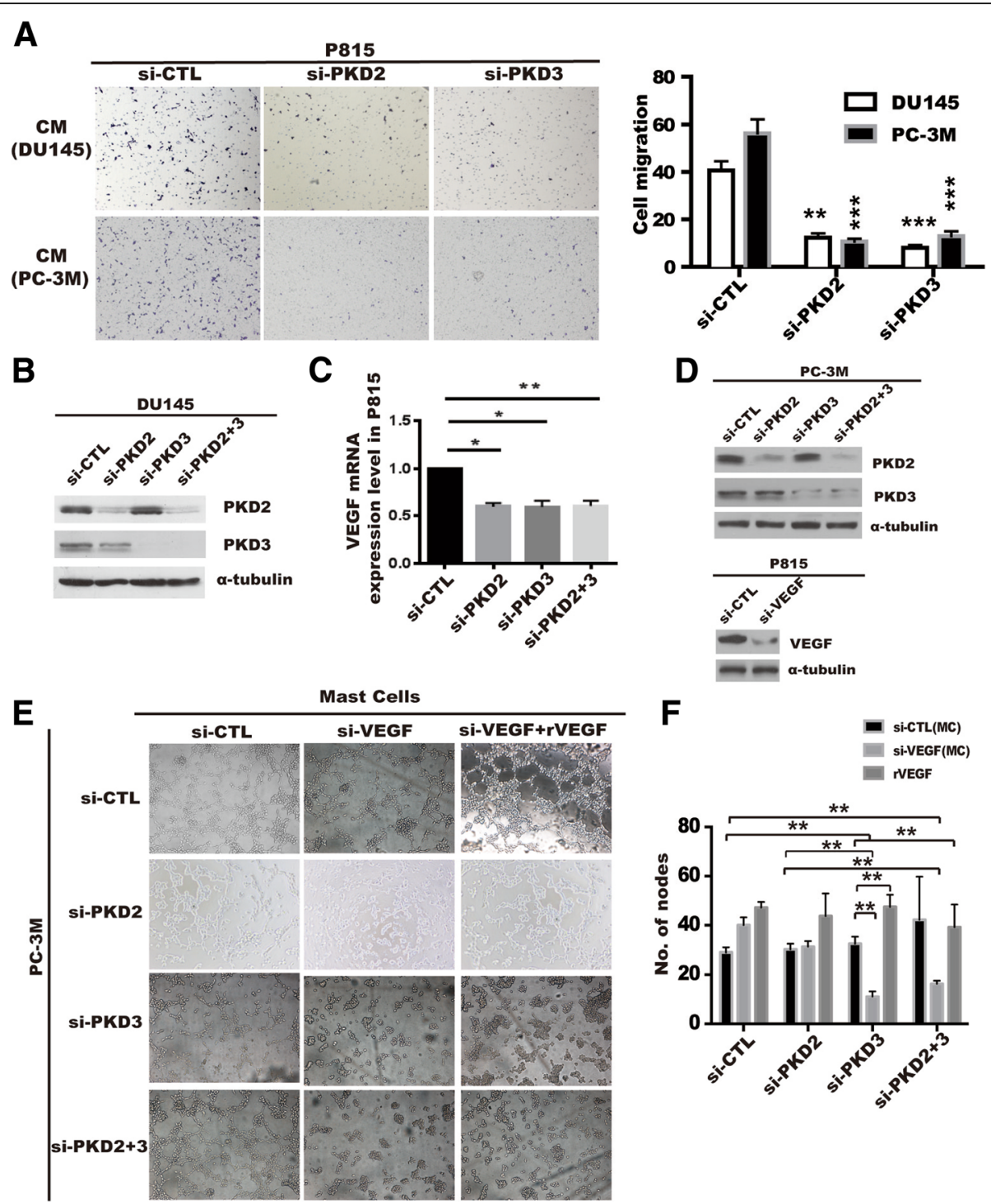

Fig. 2 Prostate cancer cells-derived PKD2/3 promote chemotactic migration of mast cells and endothelial cells tube formation. a Conditional medium (CM) from PC-3 M or DU145 cells transiently transfected with si-CTL, si-PKD2, si-PKD3 was used to be chemoattractant for P815 mast cell migration by transwell assays. ${ }^{* *} p<0.001,{ }^{* *} p<0.01$ versus si-CTL by one-way ANOVA. b Silencing of PKD2 and PKD3 verification by Western blotting (left panel). c VEGF mRNA level was assessed by qPCR in P815 mast cells induced by conditional medium from DU145 cells transfected with siRNA of PKD2 or /and PKD3 (right panel). ${ }^{*} p<0.05,{ }^{*} p<0.01$ versus si-CTL by one-way ANOVA. $\mathbf{d}$ Knockdown efficiency were verified by Western blot in PC-3 M(up) or P815 mast cells(bottom). Cells were transiently transfected with siRNA of indicated genes using lipofectmine3000. e HUVEC cells were treated with conditional medium from co-cultured of P815 mast cells transfected with si-CTL or si-VEGF and PC-3 M cells transfected with si-CTL, si-PKD2, si-PKD3 or si-PKD2 + 3. Tube formation of HUVEC cells were visualized by phase contrast inverted microscope (100x). $\mathbf{f}$ Tube formation was assessed the number of nodes per image was quantified and analyzed by two way ANOVA, ${ }^{* *} p<0.01$

respectively (Fig. 3d), specifically, depletion of PKD2 or PKD3 led a significant reduce to only $40 \%$ of control group(Fig. 3e). In line with this, similar effect was also observed in $\mathrm{PC}-3 \mathrm{M}$ cells (Additional file 8: Figure S6A-B). Moreover, SCF, a major chemotactic factor of MCs, drastically reversed inhibition of BMMCs caused by PKD2/3-depletion in DU145 cells (Additional file 8: Figure S6C-D), and knockdown effect of PKDs were verified by immunoblotting (Additional file 8: Figure S6E).
Taken together, these data suggested that PKD2/3-regulated SCF, CCL 5 and CCL11 secretion in prostate cancer cells may be the key factors that mediated migration and recruitment of MCs in tumor microenvironment.

PKD2/3 interacts with Erk1/2 and activates Erk1/2 or NFKB signaling pathway in prostate cancer cells

We previously demonstrated that PKD2 and PKD3 interact with $\mathrm{IKK} \beta$, and mediate the $\mathrm{pI \kappa B}$ kinase 
A

B
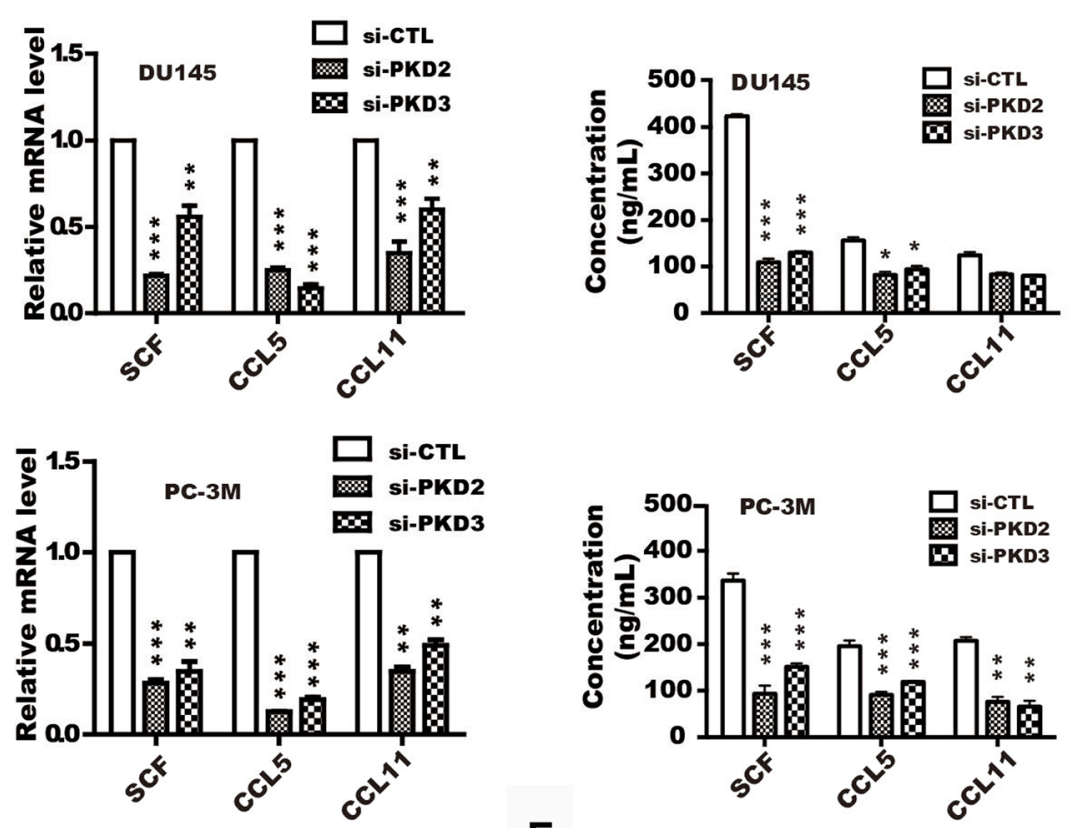

C
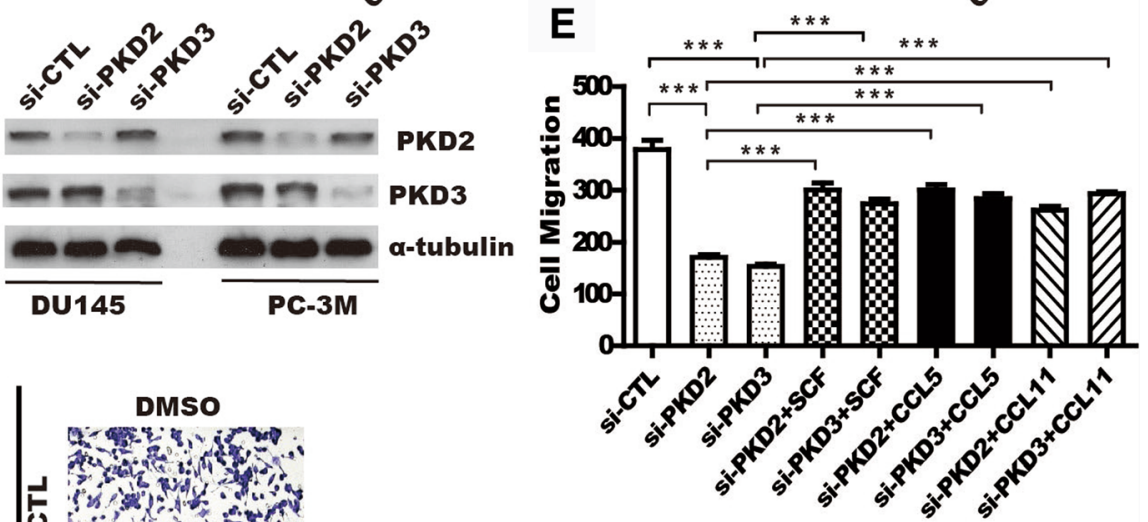

D

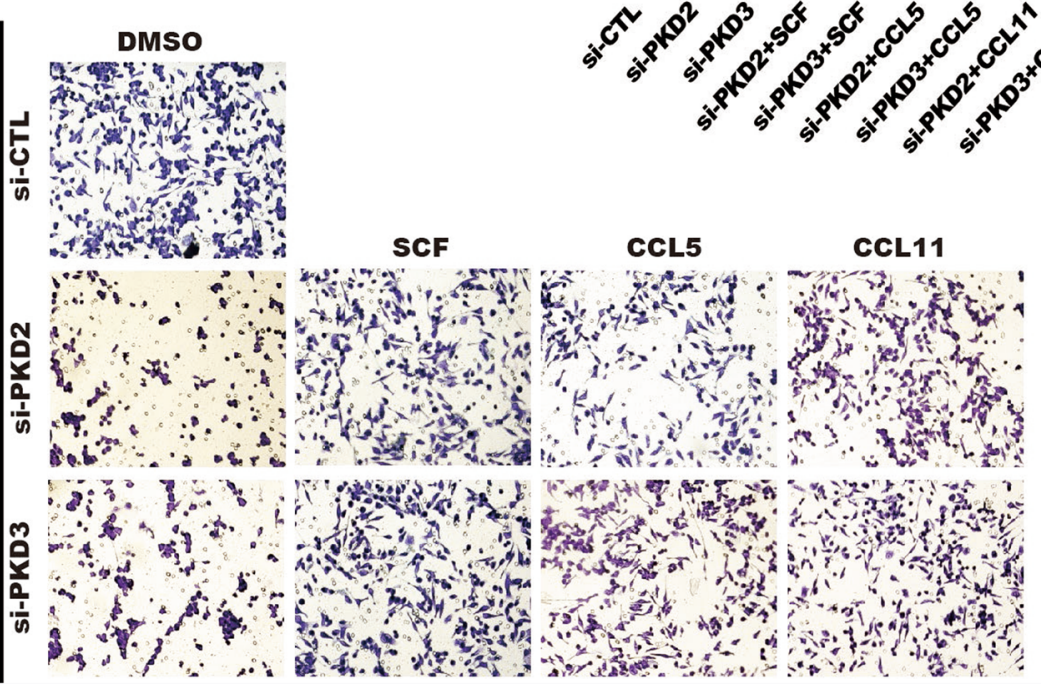

Fig. 3 PKD2/3 enhance MCs migration through upregulation of SCF, CCL5 and CCL11 in prostate cancer cellsmRNA and the protein level of the scf, ccl5 and ccl11 were analyzed by real-time qPCR and ELISA in DU145 (a) and PC-3 M (b) cells transfected with siRNA of PKD2, PKD3. Data representing the means \pm S.D. of three independent experiments was analyzed by one-way ANOVA for significance versus si-CTL. ${ }^{* * *} p<0.001$, ${ }^{* *} p<0.01,{ }^{*} p<0.05$ versus si-CTL. c Knockdown efficiency of PKD2 and PKD3 in prostate cancer cells was verified by Western blotting. $\mathbf{d}$ DU145 cells were transfected with siRNA of PKD2, PKD3, the Conditional medium (CM) was collected to measure migration of P815 cells in response to SCF, CCL5, and CCL11 treatment by transwell assay. e Quantification were analyzed from data in $D .{ }^{* *} p<0.001$ versus si-CTL by One-ANOVA tests 
(pIKK)-pІкB-ІкB degradation cascade in prostate cancer cells [35]. Moreover, NF-kB and Erk1/2 played a critical role in the regulation of cytokines and chemokines production $[38,39]$. To examine whether Erk $1 / 2$ signaling is required for PKD2/3 induced -SCF, CCL5, and CCL11 expression in tumor cells, we first analyzed the interaction of endogenous PKD2 or PKD3 with Erk1/2 in prostate cancer cells. Co-immunoprecipitation assay showed that endogenous PKD2 or PKD3 interacted with Erk1/2 in
DU145 and PC-3 M prostate cancer cells (Fig. 4a-b), but not with p38 (Additional file 9: Figure S7).

We then explored the effect of PKD2 or PKD3 on the activation of Erk1/2 or NF- $\mathrm{KB}$ signaling in response to PKDs agonist PMA in prostate cancer cells. As shown in Fig. 4c-d, basic phosphorylation of Erk1/2 and its downstream target AP-1(c-Jun:c-Fos) axis were slight reduced, while silencing of PKD2, PKD3 significant decreased activation of Erk1/2-AP axis induced by PMA
A

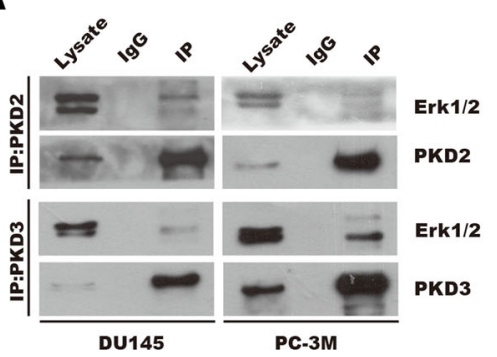

C

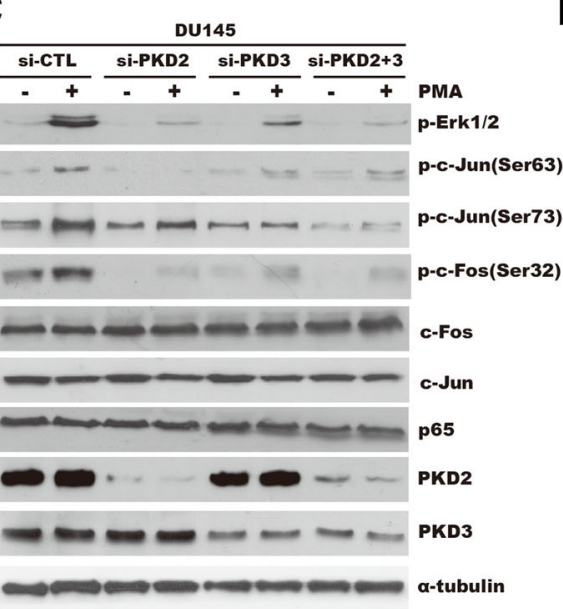

$\mathbf{E}$

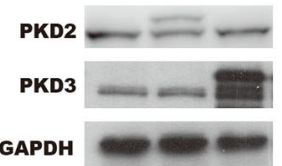

B

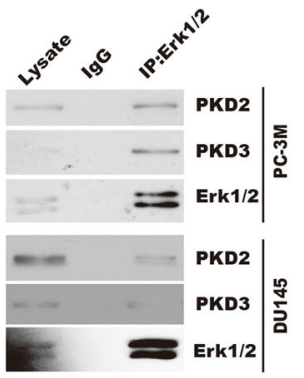

D

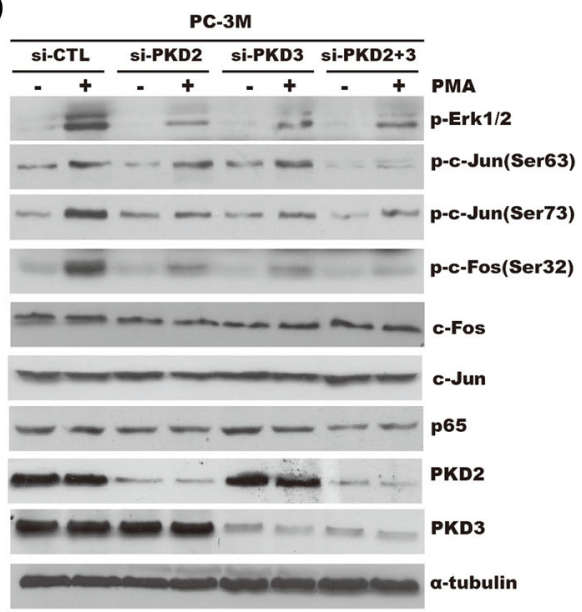

G

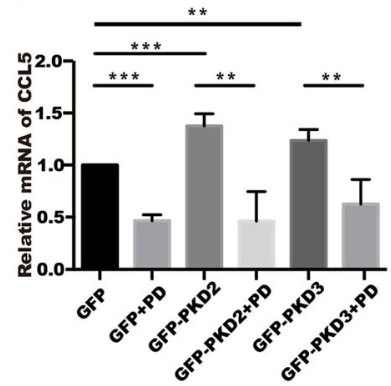

Fig. 4 PKD2 and PKD3 promote SCF, CCL5 and CCL11 expression through Erk1/2 signaling pathways. a-b Interaction of PKD2 or PKD3 with Erk1/ 2 was performed by co-IP assay in PC-3 M or DU145 prostate cancer cells. c-d DU145 cells (c) or PC-3 M cells (d) were transfected as indicated and treated with $100 \mathrm{nM}$ PMA, phosphorylation and protein expression were detected by western blotting. e Overexpression efficiency of PKD2 and PKD3 in prostate cancer cells was verified by Western blotting. $\mathbf{f}$ ELISA were applied to measure SCF in conditional medium from DU145 cell transfected with GFP, GFP-PKD2, and GFP-PKD3 in present with or without Erk inhibitor PD98059(PD) treatment. $\mathbf{g}$ Real-time PCR was performed to analyze ccl5 expression in DU145 transfected with GFP, GFP-PKD2 and GFP-PKD3 plasmids followed by treatment with or without Erk inhibitor PD98059 
treatment in DU145 and PC-3 M cells, which is also verified by quantification in DU145 cells (Additional file 10: Figure S8A-D and Figure S8I) or PC-3 M cells (Additional file 10: Figure S8E-H and Figure S8J). Similarly, NF-kB signaling was also inhibited by PKD2/3 silencing in response to PMA (Additional file 10: Figure S8K-L), which was in lined with our previous research [35]. These data suggest that Erk $1 / 2$ and NF-kB pathway might be modulated synergistically by PKD2 and PKD3 in prostate cancer cells. Next, we evaluated whether inhibition of Erk1/2 or NF-kB signaling by specific inhibitor antagonize PKD2 or PKD3 -induced chemotactic migration factor expression, such as SCF and CCL5. In prostate cancer cells with overexpressed with PKD2 and PKD3 (Fig. 4e), ELISA and RT-qPCR assay demonstrated that Erk specific inhibitor PD98059 (PD) antagonized the upregulation of SCF (Fig. 4f) and CCL5 expression (Fig. 4g) induced by PKD2 or PKD3 in DU145 cells. Similar result of $s c f, c c l 5$ and $c c l 11$ was obtained in mRNA level by treatment of NF- $\kappa B$ inhibitor BAY117082(BAY) (Additional file 11: Figure S9B) and JNK inhibitor SP600125(SP) in PC-3 cells (Additional file 11: Figure S9C-D) and DU145 cells (Additional file 11: Figure S9F-H). Collectively, these data indicate that upregulation of SCF, CCL5, and CCL11 expression triggered by PKD2/3 relies on the Erk1/2 or NF-kB signaling pathway.
PKD2/3 promotes AP-1 or NF-KB binding to the promoter of SCF, CCL5 and CCL11

Given that PKD2/3-mediated Erk1/2 or NF- $\mathrm{KB}$ signaling contributes to the upregulation of SCF, CCL5 and CCL11, and AP-1, including c-Jun and c-Fos, is a key transcriptional factor of Erk $1 / 2$ signaling [35, 40]. To further investigate whether activation of c-Jun and c-Fos or NF- $\mathrm{KB}$ induced by $\mathrm{PKD} 2 / 3$ promotes the binding of c-Jun and c-Fos or NF-kB to the promoter of $s c f, c c l 5$ and $c$ cl11

genes, we used UCSC online software to identify a putative binding sites of c-Jun and c-Fos or NF- $\mathrm{kB}$ in the promoter of $s c f, c c l 5$ and $c c l 11$ genes. Conserved binding sites of p65 and AP-1 existed in the promoter of $s c f, c c l 5$ and ccl11 genes as highlighted with $\operatorname{red}(\mathrm{p} 65)$ and blue(AP-1), respectively (Fig. 5a). Chromatin Immunoprecipitation (ChIP) followed by RT-qPCR showed that PKD2 or PKD3 silencing significantly reduced c-Jun:c-Fos, two subunit of AP-1, binding to the promoter of $s c f, c c l 5$, and $c c l 11$, respectively (Fig. 5c and d). Similar effect of PKD2/3 depletion on NF-kB binding to the promoter of above genes was also observed (Fig. 5e). Meanwhile, Knockdown of PKD2 or PKD3 in DU145 cells was verified by Western blotting (Fig. 5b). Taken together, these results indicate that AP- 1 and NF- $\mathrm{kB}$ play

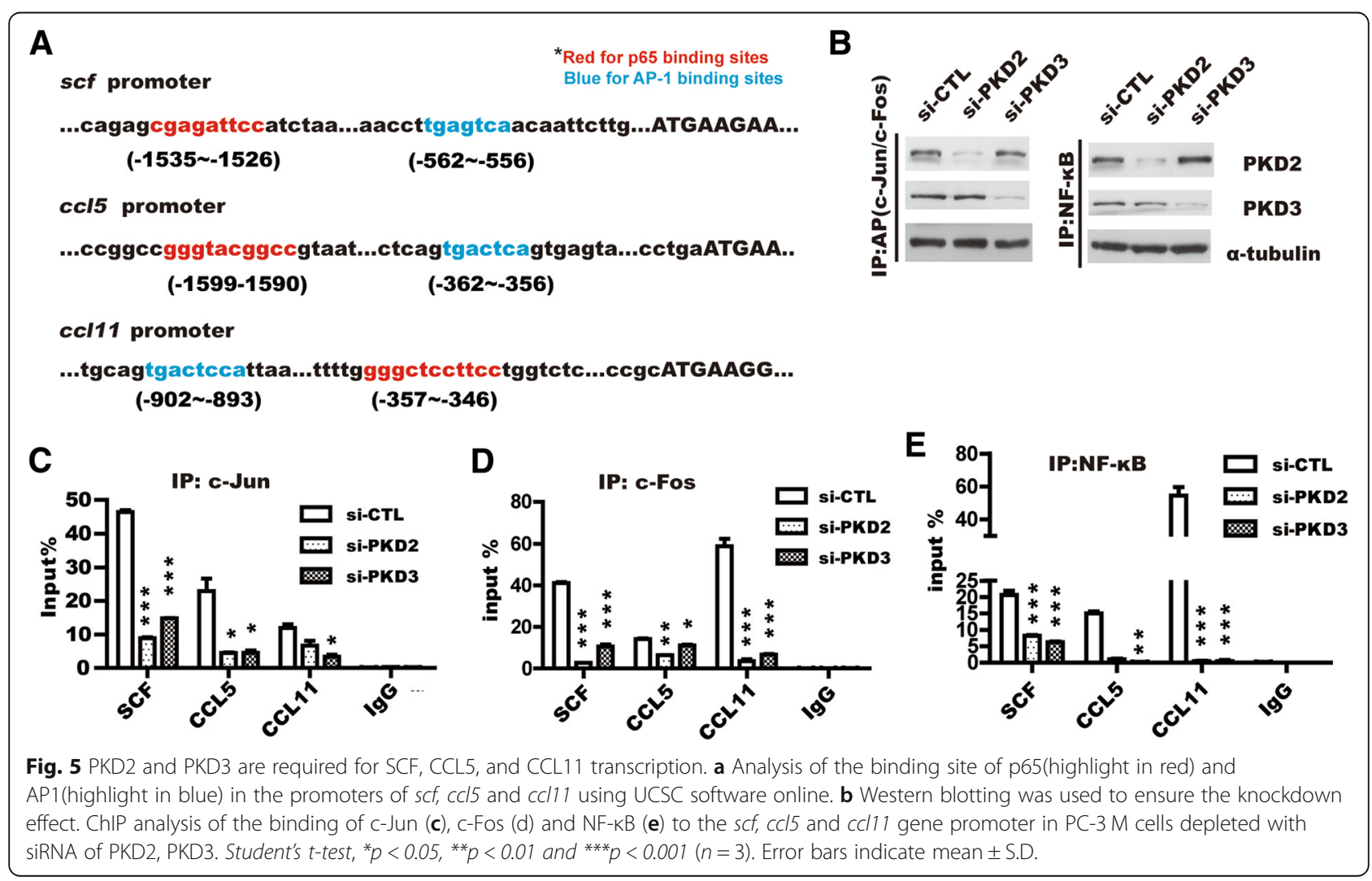


a central role in the transactivation of $s c f, c c l 5$ and $c c l 11$ induced by PKD2 or PKD3 in prostate cancer cells.

\section{Inhibition of PKD represses MCs infiltration, tumor} angiogenesis and tumor growth in vivo

CRT0066101, a newly developed PKD inhibitor, has been demonstrated to inhibit cancer growth in multiple cancer models [41, 42]. To provide insights into the effect of PKD2/PKD3 on the recruitment of MCs, tumor angiogenesis and tumor growth in prostate cancer model, mouse prostate cancer RM1 cells were injected subcutaneously into C57BL/6 mice, mice with RM1 tumors were randomized to three groups as described in method (Fig. 6a). After 2 weeks of treatment, both tumor size (Fig. 6b) and tumor volume (Fig. 6c) were inhibited by CRT0066101 inhibitor, whereas body weight was no changed even at the highest dose of CRT0066101 (Additional file 12: Figure S10). Moreover, CRT066101 treatment resulted in a dose-dependent suppression of PKD activity (phospho-PKD), MC recruitment (c-Kit), and the level of MVD (Fig. 6d and Additional file 1: Table S6). Taken together, these data provide evidence

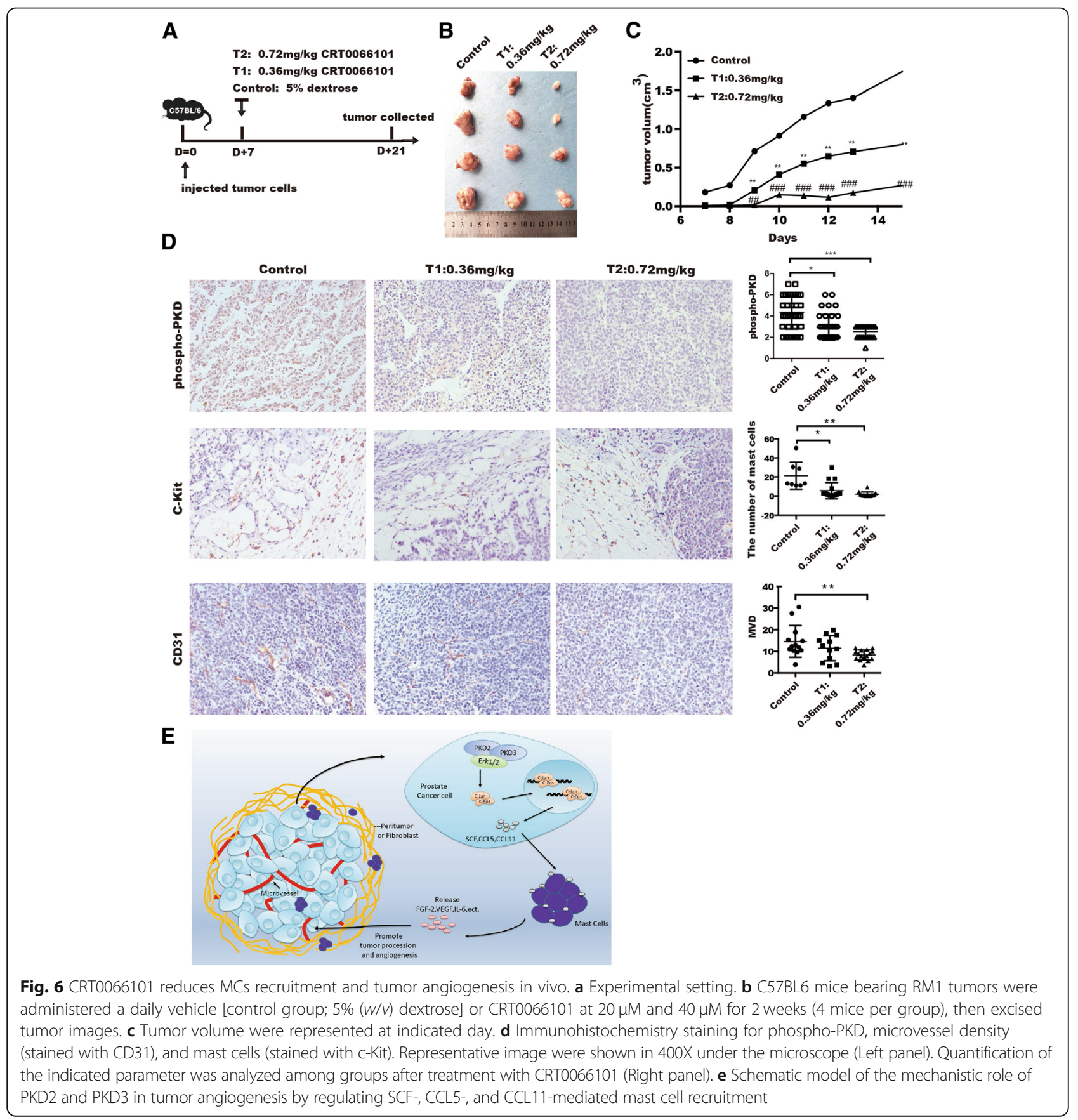


that PKD2 and PKD3 could promote prostate cancer progression through the recruitment of MCs and tumor angiogenesis in prostate cancer microenvironment.

\section{Discussion}

In this study, we have demonstrated that knockdown of PKD2/3 or inhibition of PKD activity in prostate cancer cells in vitro significantly repressed MCs recruitment through regulating AP-1 or NF- $\mathrm{kB}$ mediated transcription of SCF, CCL5 and CCL11, thereby inhibiting angiogenic factors expression in MCs. Enhanced activation of PKD was correlated with tumor angiogenesis in prostate tumor tissues compared with the normal tissues. Moreover, PKD inhibitor CRT0066101 attenuated tumor angiogenesis as well as tumor growth in vivo. These findings indicate PKDs are crucial mediator of MC recruitment in prostate cancer, and could be targeted to inhibit $\mathrm{MC}$ infiltration and $\mathrm{MC}$-induced tumor angiogenesis.

Our previous studies have demonstrated a significant role of PKDs in prostate cancer cell invasion [35], proliferation, tumor growth [21] and survival [20]. However, the functional role of PKD in tumor angiogenesis is not fully elucidated. Angiogenesis, which plays an important role in immune response, inflammation and tumor progression, is a critical component of tumor microenvironment and increases oxygen, tumor invasion and migration [43-45]. We revealed a positive correlation of PKD activation with MCs recruitment and angiogenesis in prostate cancer.

Interestingly, our pervious results showed that both PKD2 and PKD3 have failed to alter VEGF mRNA expression [35]. In the present study, we found that PKD2 and PKD3 did not directly promote the tube formation of endothelial cells using co-culture with HUVEC cells directly, which imply that PKD2 and PKD3 may promote angiogenesis by remodeling tumor microenvironment. MCs are present in $95.9 \%$ of the tumor samples $[46,47]$, showing versatile roles from dangerous promoters, innocent bystanders, to essential guardians of tumors, depending on the stage and origin of carcinoma [9]. High intratumoral mast cell density is associated with favorable tumor characteristics and good prognosis in prostate cancer $[15,48]$, oppositely high peritumoral mast cells density process tumor cell proliferation, neo-angiogenesis, invasion and metastasis [47, 49]. Also, our finding showed that PKD2/3 of prostate cancer cells was involved in MCs recruitment and angiogenic factors expression in MCs leading to angiogenesis. Furthermore, Inhibition of PKD by CRT0066101 significantly reduced microvessel density in vivo, which are largely attributed to reduce MCs migration. Nevertheless, a recent report showed that pure presence of mast cells in tumor microenvironment does not necessarily have any functional impact on tumor growth, tumor progression or tumor vascularization [50]. These controversial findings remind us that it is of importance to seek specific marker for clarification of intratumoral and peritumoral mast cells as well as corresponding function in tumor microenvironment.

Much more evidences supported that PKD2/3 promoted inflammation and tumor procession in carcinoma and its microenvironments by regulating different cytokine expression and secretion. PKD2 regulated tumor migration and invasion via MAPK pathway, p53-dependent and -independent pathways in tumor progression [22, 51]. Meanwhile, PKD3 was an inconspicuous isoform in PKDs family, which not only regulates tumor invasion in breast cancer but also contributes to HIV-1 provirus binding to the promoter of NF- $\mathrm{kB}$ [52]. The current study indicated that PKD2 and PKD3 have a critical role in the regulation of SCF, CCL5, and CCL11 expression, which are pivotal for MC infiltration [23, 36]. Given that PKD2 and PKD3 contributions to NF- $\mathrm{KB}$ signaling has been well documented in our previous work. Depletion of PKD2 and PKD3 in prostate cancer cells significantly decreased binding of p65, c-Jun and c-Fos to the scf, $c c l 5$, and $c c l 11$ promoter. Collectively, these results indicated that PKD2/ 3-NF- $\mathrm{BB}$ and PKD2/3-Erk1/2 axes played an important role in prostate cancer cell.

\section{Conclusions}

In summary, the current study showed that PKDs serve as a pro-angiogenic molecular by recruitment of mast cells in tumor microenvironment of prostate cancer. We demonstrated that PKD2 and PKD3 played a critical role in the regulation of tumor angiogenesis and defined a novel model in which PKD2 and PKD3 activate Erk1/2 and NF- $\mathrm{KB}$ in prostate cancer cells through promoting SCF, CCL5, and CCL11 expression, which further promote MCs recruitment and expression of angiogenic factors consequently, leading to tumor angiogenesis (Fig. 6e). Most importantly, inhibition of PKD2 and PKD3 largely blocked tumor growth and angiogenesis in vivo. This finding not only provided further support for the notion that cancer cells shape a tumor microenvironment that is favorable for facilitating tumor progression, but also added a novel molecular link between tumor biology and tumor angiogenesis.

\section{Additional files}

Additional file 1: Table S1-S6. (DOCX $18 \mathrm{~kb})$

Additional file 2: Supplementary data. (DOCX $21 \mathrm{~kb})$

Additional file 3: Figure S1. mRNA level of PKD1/2/3 expression from prostate cancer TCGA data. (PDF 64 kb)

Additional file 4: Figure S2. Autophosphorylation of PKD at s916 in prostate tissue. (PDF $1121 \mathrm{~kb}$ ) 
Additional file 5: Figure S3. PKD2/3 in prostate cancer cells promoted chemotactic migration of mast cells. (PDF $1025 \mathrm{~kb}$ )

Additional file 6: Figure S4. Effect of PKD2 and PKD3 derived prostate cancer cells on endothelial cells tube formation in vitro. (PDF $832 \mathrm{~kb}$ )

Additional file 7: Figure S5. PKD2/3 silencing of prostate cancer cells reduced angiogenic factor expression in P815 MCs cells. (PDF 785 kb)

Additional file 8: Figure S6. SCF, CCL5, and CCL11 rescued MCs migration inhibited by CM from PC-3M cells with PKD silencing (PDF $2500 \mathrm{~kb}$ )

Additional file 9: Figure S7. PKD2/3 did not interact with p38. (PDF $466 \mathrm{~kb})$

Additional file 10: Figure S8. PKD2/3 modulated Erk1/2 and NF-KB activity in prostate cancer cells in response to PMA. (PDF $812 \mathrm{~kb}$ )

Additional file 11: Figure S9. NF-KB and JNK inhibitor antagonized SCF, CCL5 and CCL11 mRNA level induced by PKD2 or PKD3 overexpression in DU145 cells (PDF $1352 \mathrm{~kb}$ )

Additional file 12: Figure S10. Effect of PKD inhibitor on body weight change in vivo. (PDF $514 \mathrm{~kb}$ )

\section{Abbreviations}

BMMCs: Bone marrow derived mast cells; CCL11: Chemokine ligand 11; CCL5: Chemokine ligand 5; Erk: Extracellular regulated protein kinases; FGF2: Fibroblast growth factor; IKKa/B: Inhibitor of nuclear factor kappa-B kinase; IL: Interleukin; IKB: Inhibitor of nuclear factor kappa-B; MCs: Mast cells; NFKB: Nuclear factor kappa-B; PKC: Protein kinase C; PKD: Protein kinase D; PMA: Phorbol-12-myristate-13-acetate; SCF: Stem cell factor; TNF-a: Tumor Necrosis Factor; VEGF: Vascular endothelial growth factor

\section{Acknowledgments}

We deeply thank Deng's research group in Southern Medical University for many supports to us. Specially, thanks Xing Zhe, Li Shao and Wang Yaodong for giving kindly technical support to us all the time.

\section{Funding}

The work was supported in part by the National Natural Science Foundation of China (grant NO. 81272852, 81472407, 81772761; 81672540); Oversea Hong Kong \& Macao Scholars Collaborative Research Fund of NSFC in China (Grant NO. 81328020); Science and Technology Project of Guangzhou (Grant NO. 210707010303; 201607010351).

\section{Availability of data and materials}

All data generated and analyzed in this study was included in this manuscript and its additional files.

\section{Authors' contributions}

WF.X, JB.Q, FY.Z, SY.L, performed most of the experiments, analyzed the data and wrote the manuscript. WJ.G, LP.C, GH.L, ZS.Z, performed some experiments and analyzed the data. QJ.W and F.D conceived, designed the experiments and revised the manuscript. All authors read and approved the final manuscript.

\section{Ethics approval}

All animal experiments were conducted according to Southern Medical University's animal institutional regulations and the relevant authorities approved the research protocols.

\section{Consent for publication}

All authors agreed on the manuscript publication.

\section{Competing interests}

The authors declare that they have no competing interests.

\section{Publisher's Note}

Springer Nature remains neutral with regard to jurisdictional claims in published maps and institutional affiliations.

\section{Author details}

'Department of Cell Biology, School of Basic Medical Sciences, Southern Medical University, Guangzhou 510515, China. ${ }^{2}$ Department of Clinical Laboratory, The Fifth Affiliated Hospital, Southern Medical University, Guangzhou 510900, China. ${ }^{3}$ Department of Pharmacology and Chemical Biology, University of Pittsburgh School of Medicine, Pittsburgh, PA 15261, USA. ${ }^{4}$ Present address: Guangzhou Institute of Pediatrics, Guangzhou Women and Children's Medical Center, Guangzhou Medical University, Guangzhou 510623, China.

Received: 29 October 2018 Accepted: 22 February 2019

Published online: 06 March 2019

\section{References}

1. Attard G, Parker C, Eeles RA, Schroder F, Tomlins SA, Tannock I, et al. Prostate cancer. Lancet. 2016 Jan 2;387(10013):70-82.

2. Litwin MS, Tan HJ. The diagnosis and treatment of prostate Cancer: a review. Jama. 2017;317(24):2532-42.

3. Chen W, Zheng R, Baade PD, Zhang S, Zeng H, Bray F, et al. Cancer statistics in China, 2015. CA Cancer J Clin. 2016:66(2):115-32.

4. Nakamura K, Smyth MJ. Targeting cancer-related inflammation in the era of immunotherapy. Immunol Cell Biol. 2017:95(4):325-32.

5. Pinato DJ. Cancer-related inflammation: an emerging prognostic domain in metastatic castration-resistant prostate carcinoma. Cancer. 2014; 120(21):3272-4

6. Galli SJ, Kalesnikoff J, Grimbaldeston MA, Piliponsky AM, Williams CM, Tsai M Mast cells as "tunable" effector and immunoregulatory cells: recent advances. Annu Rev Immunol. 2005:23:749-86.

7. Kalesnikoff J, Galli SJ. New developments in mast cell biology. Nat Immunol. 2008;9(11):1215-23.

8. $\quad$ Dang Q, Li L, Xie H, He D, Chen J, Song W, et al. Anti-androgen enzalutamide enhances prostate cancer neuroendocrine (NE) differentiation via altering the infiltrated mast cells --> androgen receptor (AR) --> miRNA32 signals. Mol Oncol. 2015;9(7):1241-51.

9. Pittoni P, Colombo MP. The dark side of mast cell-targeted therapy in prostate cancer. Cancer Res. 2012;72(4):831-5.

10. Ribatti D, Ennas MG, Vacca A, Ferreli F, Nico B, Orru S, et al. Tumor vascularity and tryptase-positive mast cells correlate with a poor prognosis in melanoma. Eur J Clin Investig. 2003;33(5):420-5.

11. Beer TW, Ng LB, Murray K. Mast cells have prognostic value in Merkel cell carcinoma. Am J Dermatopathol. 2008;30(1):27-30.

12. Groot Kormelink T, Abudukelimu A, Redegeld FA. Mast cells as target in cancer therapy. Curr Pharm Des. 2009;15(16):1868-78.

13. Aydin O, Dusmez D, Cinel L, Doruk E, Kanik A. Immunohistological analysis of mast cell numbers in the intratumoral and peritumoral regions of prostate carcinoma compared to benign prostatic hyperplasia. Pathol Res Pract. 2002;198(4):267-71.

14. Nonomura N, Takayama H, Nishimura K, Oka D, Nakai Y, Shiba M, et al. Decreased number of mast cells infiltrating into needle biopsy specimens leads to a better prognosis of prostate cancer. Br J Cancer. 2007:97(7):952-6.

15. Johansson A, Rudolfsson S, Hammarsten P, Halin S, Pietras K, Jones J, et al. Mast cells are novel independent prognostic markers in prostate cancer and represent a target for therapy. Am J Pathol. 2010;177(2):1031-41.

16. Pittoni P, Tripodo C, Piconese S, Mauri G, Parenza M, Rigoni A, et al. Mast cell targeting hampers prostate adenocarcinoma development but promotes the occurrence of highly malignant neuroendocrine cancers. Cancer Res. 2011:71(18):5987-97.

17. Chen LA, Li J, Silva SR, Jackson LN, Zhou Y, Watanabe H, et al. PKD3 is the predominant protein kinase $D$ isoform in mouse exocrine pancreas and promotes hormone-induced amylase secretion. J Biol Chem. 2009;284(4): 2459-71.

18. Aziz MH, Manoharan HT, Sand JM, Verma AK. Protein kinase Cepsilon interacts with Stat3 and regulates its activation that is essential for the development of skin cancer. Mol Carcinog. 2007:46(8):646-53.

19. Huck B, Duss S, Hausser A, Olayioye MA. Elevated protein kinase D3 (PKD3) expression supports proliferation of triple-negative breast cancer cells and contributes to mTORC1-S6K1 pathway activation. J Biol Chem. 2014:289(6):3138-47.

20. Chen J, Deng F, Singh SV, Wang QJ. Protein kinase D3 (PKD3) contributes to prostate cancer cell growth and survival through a PKCepsilon/PKD3 pathway downstream of Akt and ERK 1/2. Cancer Res. 2008;68(10):3844-53. 
21. Tandon M, Salamoun JM, Carder EJ, Farber E, Xu S, Deng F, et al. SD-208, a novel protein kinase D inhibitor, blocks prostate cancer cell proliferation and tumor growth in vivo by inducing G2/M cell cycle arrest. PLoS One. 2015;10(3):e0119346.

22. Azoitei N, Pusapati GV, Kleger A, Moller P, Kufer R, Genze F, et al. Protein kinase D2 is a crucial regulator of tumour cell-endothelial cell communication in gastrointestinal tumours. Gut. 2010;59(10):1316-30.

23. Huang B, Lei Z, Zhang GM, Li D, Song C, Li B, et al. SCF-mediated mast cell infiltration and activation exacerbate the inflammation and immunosuppression in tumor microenvironment. Blood. 2008;112(4):1269-79.

24. Wu SY, Rupaimoole R, Shen F, Pradeep S, Pecot CV, Ivan C, et al. A miR-192EGR1-HOXB9 regulatory network controls the angiogenic switch in cancer. Nat Commun. 2016;7:11169.

25. Xu W, Zhang Z, Zou K, Cheng Y, Yang M, Chen H, et al. MiR-1 suppresses tumor cell proliferation in colorectal cancer by inhibition of Smad3mediated tumor glycolysis. Cell Death Dis. 2017:8(5):e2761.

26. LaValle CR, Zhang L, Xu S, Eiseman JL, Wang QJ. Inducible silencing of protein kinase D3 inhibits secretion of tumor-promoting factors in prostate cancer. Mol Cancer Ther. 2012;11(7):1389-99.

27. Danelli L, Frossi B, Gri G, Mion F, Guarnotta C, Bongiovanni L, et al. Mast cells boost myeloid-derived suppressor cell activity and contribute to the development of tumor-favoring microenvironment. Cancer immunology research. 2015;3(1):85-95.

28. Hugo HJ, Lebret S, Tomaskovic-Crook E, Ahmed N, Blick T, Newgreen DF, et al. Contribution of fibroblast and mast cell (afferent) and tumor (efferent) IL6 effects within the tumor microenvironment. Cancer Microenviron. 2012; 5(1):83-93.

29. Liu J, Zhang Y, Zhao J, Yang Z, Li D, Katirai F, et al. Mast cell: insight into remodeling a tumor microenvironment. Cancer Metastasis Rev. 2011;30(2): $177-84$.

30. Jaggi M, Rao PS, Smith DJ, Hemstreet GP, Balaji KC. Protein kinase C mu is down-regulated in androgen-independent prostate cancer. Biochem Biophys Res Commun. 2003;307(2):254-60.

31. Guo J, Clausen DM, Beumer JH, Parise RA, Egorin MJ, Bravo-Altamirano K, et al. In vitro cytotoxicity, pharmacokinetics, tissue distribution, and metabolism of small-molecule protein kinase D inhibitors, kb-NB142-70 and kb-NB165-09, in mice bearing human cancer xenografts. Cancer Chemother Pharmacol. 2013;71(2):331-44.

32. Toth $T$, Toth-Jakatics $R$, Jimi S, Takebayashi S. Increased density of interstitial mast cells in amyloid a renal amyloidosis. Mod Pathol. 2000;13(9):1020-8.

33. Sawatsubashi M, Yamada T, Fukushima N, Mizokami H, Tokunaga O, Shin T. Association of vascular endothelial growth factor and mast cells with angiogenesis in laryngeal squamous cell carcinoma. Virchows Archiv. 2000:436(3):243-8

34. Coussens LM, Raymond WW, Bergers G, Laig-Webster M, Behrendtsen O, Werb $Z$, et al. Inflammatory mast cells up-regulate angiogenesis during squamous epithelial carcinogenesis. Genes Dev. 1999;13(11):1382-97.

35. Zou Z, Zeng F, Xu W, Wang C, Ke Z, Wang QJ, et al. PKD2 and PKD3 promote prostate cancer cell invasion by modulating NF-kappaB- and HDAC1-mediated expression and activation of UPA. J Cell Sci. 2012;125(Pt 20:4800-11.

36. Juremalm M, Olsson N, Nilsson G. CCL17 and CCL22 attenuate CCL5induced mast cell migration. Clin Exp Allergy. 2005;35(6):708-12.

37. Zweifel M, Matozan K, Dahinden C, Schaffner T, Mohacsi P. Eotaxin/CCL11 levels correlate with myocardial fibrosis and mast cell density in native and transplanted rat hearts. Transplant Proc. 2010;42(7):2763-6.

38. Mendez-Samperio P, Trejo A, Perez A. Mycobacterium bovis bacillus Calmette-Guerin induces CCL5 secretion via the toll-like receptor 2-NFkappaB and -Jun N-terminal kinase signaling pathways. Clin Vaccine Immunol. 2008;15(2):277-83.

39. Yeligar SM, Machida K, Tsukamoto H, Kalra VK. Ethanol augments RANTES/ CCL5 expression in rat liver sinusoidal endothelial cells and human endothelial cells via activation of NF-kappa B, HIF-1 alpha, and AP-1. J Immunol. 2009;183(9):5964-76.

40. Luo G, Cheng BC, Zhao H, Fu XQ, Xie R, Zhang SF, et al. Schisandra Chinensis Lignans suppresses the production of inflammatory mediators regulated by NF-kappaB, AP-1, and IRF3 in lipopolysaccharide-stimulated RAW264.7 cells. Molecules (Basel, Switzerland). 2018;23(12):pii: E3319.

41. Harikumar KB, Kunnumakkara AB, Ochi N, Tong Z, Deorukhkar A, Sung B, et al. A novel small-molecule inhibitor of protein kinase $D$ blocks pancreatic cancer growth in vitro and in vivo. Mol Cancer Ther. 2010;9(5):1136-46.
42. Li QQ, Hsu I, Sanford T, Railkar R, Balaji N, Sourbier C, et al. Protein kinase D inhibitor CRT0066101 suppresses bladder cancer growth in vitro and xenografts via blockade of the cell cycle at G2/M. Cell Mol Life Sci. 2018; 75(5):939-63.

43. Cully M. Cancer: tumour vessel normalization takes Centre stage. Nat Rev Drug Discov. 2017;16(2):87.

44. Liu LZ, Ding M, Zheng JZ, Zhu Y, Fenderson BA, Li B, et al. Tungsten carbide-cobalt nanoparticles induce reactive oxygen species, AKT, ERK, AP-1, NF-kappaB, VEGF, and angiogenesis. Biol Trace Elem Res. 2015;166(1):57-65.

45. Xu Q, Liu LZ, Yin Y, He J, Li Q, Qian X, et al. Regulatory circuit of PKM2/NFkappaB/miR-148a/152-modulated tumor angiogenesis and cancer progression. Oncogene. 2015;34(43):5482-93.

46. Galinsky DS, Nechushtan H. Mast cells and cancer--no longer just basic science. Crit Rev Oncol Hematol. 2008;68(2):115-30.

47. Khazaie K, Blatner NR, Khan MW, Gounari F, Gounaris E, Dennis K, et al. The significant role of mast cells in cancer. Cancer Metastasis Rev. 2011; 30(1):45-60.

48. Fleischmann A, Schlomm T, Kollermann J, Sekulic N, Huland H, Mirlacher M, et al. Immunological microenvironment in prostate cancer: high mast cell densities are associated with favorable tumor characteristics and good prognosis. Prostate. 2009;69(9):976-81.

49. Sfanos KS, Hempel HA, De Marzo AM. The role of inflammation in prostate cancer. Adv Exp Med Biol. 2014;816:153-81.

50. Ghouse SM, Polikarpova A, Muhandes L, Dudeck J, Tantcheva-Poor I, Hartmann K, et al. Although abundant in tumor tissue, mast cells have no effect on immunological micro-milieu or growth of HPV-induced or transplanted tumors. Cell Rep. 2018;22(1):27-35.

51. Bernhart E, Damm S, Wintersperger A, DeVaney T, Zimmer A, Raynham T, et al. Protein kinase D2 regulates migration and invasion of U87MG glioblastoma cells in vitro. Exp Cell Res. 2013;319(13):2037-48.

52. Liu Y, Li J, Zhang J, Yu Z, Yu S, Wu L, et al. Oncogenic protein kinase D3 regulating networks in invasive breast Cancer. Int J Biol Sci. 2017;13(6):748-58.

\section{Ready to submit your research? Choose BMC and benefit from:}

- fast, convenient online submission

- thorough peer review by experienced researchers in your field

- rapid publication on acceptance

- support for research data, including large and complex data types

- gold Open Access which fosters wider collaboration and increased citations

- maximum visibility for your research: over $100 \mathrm{M}$ website views per year

At BMC, research is always in progress.

Learn more biomedcentral.com/submissions 